Article

\title{
Simple Preparation of Diverse Neoagaro-Oligosaccharides
}

\author{
Fudi Lin ${ }^{1}$, Jing Ye ${ }^{1,2}$, Yayan Huang ${ }^{1,2}$, Yucheng Yang ${ }^{1,2, * \mathbb{C}}$ and Meitian Xiao ${ }^{1,2, *}$ \\ 1 College of Chemical Engineering, Huaqiao University, Xiamen 361021, China; 15105966539@163.com (F.L.); \\ yejenny@hqu.edu.cn (J.Y.); yyhuang@hqu.edu.cn (Y.H.) \\ 2 Xiamen Engineering and Technological Research Center for Comprehensive Utilization of Marine Biological \\ Resources, Xiamen 361021, China \\ * Correspondence: yangyc@hqu.edu.cn (Y.Y.); mtxiao@hqu.edu.cn (M.X.)
}

Received: 2 April 2019; Accepted: 2 May 2019; Published: 7 May 2019

\begin{abstract}
A simple method for obtaining pure and well-defined oligosaccharides was established by hydrolyzing agar with $\beta$-agarase from Vibrio natriegens. The conditions for enzymolysis were optimized as follows: a temperature of $45^{\circ} \mathrm{C}$, a pH of 8.5 , a substrate concentration of $0.3 \%$, an enzyme amount of $100 \mathrm{U} / \mathrm{g}$ and an enzymolysis time of $20 \mathrm{~h}$. Neoagaro-oligosaccharides with different degrees of polymerization were obtained by hydrolyzing agar with $\beta$-agarase for different lengths of time. After removing pigments using activated carbon and salts by dialyzing, the enzyme hydrolysis solution was separated with Bio-Gel P2 column chromatography. Neoagaro-oligosaccharides with different degrees of polymerization were acquired. By comparing with authentic standard substances, along with further confirmation by FTIR, MS and NMR, structures of the purified neoagaro-oligosaccharides were identified as neoagarobiose (NA2), neoagaroteraose (NA4), neoagarohexaose (NA6), neoagarooctaose (NA8), neoagaro-decaose (NA10) and neoagarododecaose (NA12) with purities of more than $97.0 \%$. The present study established a method for the preparation of various neoagaro-oligosaccharides that may be of great significance for further study of their bioactivities.
\end{abstract}

Keywords: agar; enzymatic hydrolysis; neoagaro-oligosaccharides; separation

\section{Introduction}

Agar, an important marine polysaccharide extracted from the cell walls of red algae, is a linear polymer containing $(1 \rightarrow 4)$-linked 3,6-anhydro- $\alpha$-L-galactose and $(1 \rightarrow 3)$-linked $\beta$-D-galactopyranose [1], and it is composed of agarose and agaropectin [2]. Agar is widely used in the food, biological, and pharmaceutical industries [3]. Accumulating reports have indicated that the oligosaccharides prepared from agar/agarose have diverse physiological functions, such as antioxidant [4-9], anti-hyperlipidemia [9-11], anti-inflammation [12-14] activity, and a whitening effect [15,16], which will expand their use in the food, cosmetic, and medical industries.

Generally, oligosaccharides from agar/agarose can be classified as either agaro-oligosaccharides (AOS) with agarobiose as a repeating unit (Figure 1A) [17-19] or neoagaro-oligosaccharides (NAOS) with neoagarobiose as a repeating unit (Figure 1B) [20-22]. The former are the hydrolysis products of acid or $\alpha$-agarase which cleaves the $\alpha-(1 \rightarrow 3)$-galactosidic bond of the polysaccharides (Figure $1 \mathrm{~A})$, and the latter are hydrolysates of $\beta$-agarase which splits the $\beta-(1 \rightarrow 4)$ bond (Figure 1B). AOS and NAOS with different degrees of polymerization (DP) have been reported to possess various bioactivities. A large number of reports indicated that AOS have beneficial antioxidant [4-8], anti-obesity [10,11], anti-inflammation [12-14], anti-cancer [23] activity, and also protect the intestine [10,11,23]. In recent years, NAOS mixtures, as well as NOAS of signal DP, have attracted increasing attention for their distinct physiological and biological activities. According to the reported prebiotic studies, the NAOS 
mixtures show varying activity in antioxidants [24]. In addition, the NAOS with DP of 4-12 could increase the amount of lactobacilli and bifidobacteri in vivo, suggesting that they had beneficial probiotic effects [25]. Neoagarobiose (NA2), neoagaroteraose (NA4), and neoagarohexaose (NA6) were reported to have in vitro skin whitening and moisturizing effects, among them, NA4 was found to be a better whitening agent than the other two, whereas AOS did not exhibit the same activities $[15,16]$. Moreover, NA4 displayed a better ability to scavenge hydroxyl radicals compared to that of NA2, NA6, and neoagarooctaose (NA8), meanwhile, agarotriose and agarobiose are not able to scavenge hydroxyl radicals. Additionally, NA4 was proved to inhibit inflammation in LPS-stimulated macrophages through suppression of mitogen-activated protein kinase (MAPK) and NF- $\mathrm{BB}$ pathways [26,27].

(A)

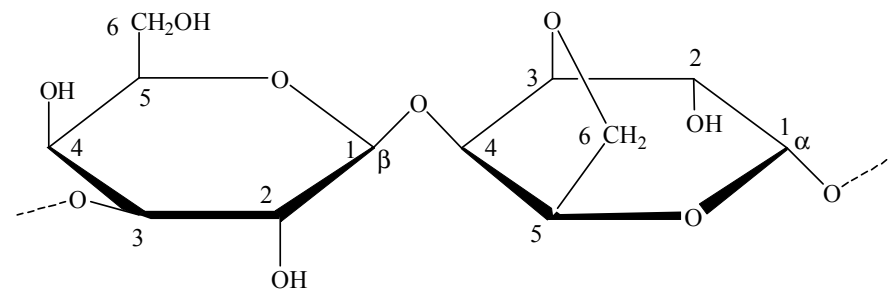

(B)

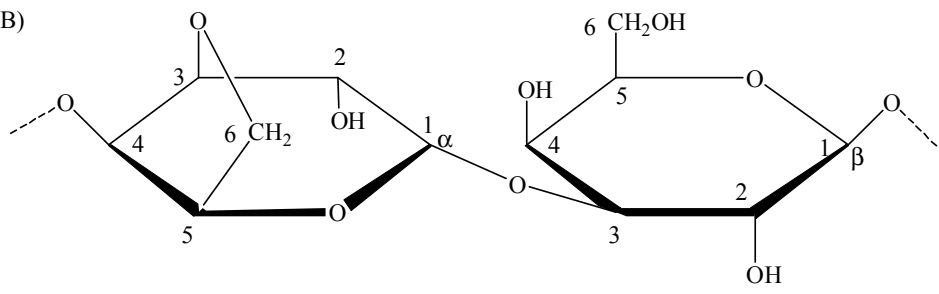

Figure 1. Structure of agarobiose (A) and neoagarobiose (B).

Notably, these studies mainly focused on the activities of NAOS mixture, NA2, NA4, and NA6, while few reports have investigated the bioactivities of NAOS with higher DP such as NA8, neoagarodecaose (NA10), and neoagarododecaose (NA12). The reasons for this may be attributed to the difficulty of obtaining NAOS with higher DP and the complexity of their purification. Many efforts have been devoted to obtaining NAOS. $\beta$-agarases from marine bacterium Janthinobacterium sp. SY12, Vibrio sp. Strain JT0107, Agarivorans albus YKW-34 and Agarivorans albus OAY02 were employed to degrade agarose to give NA2 and NA4 [28-30]. $\beta$-agarase obtained from Microbulbifer sp. Q7, marine Alteromonas sp. SY37-12, Pseudoalteromonas sp. CY24, marine Agarivorans sp. LQ48 and Pseudoalteromonas sp. AG4 could hydrolyze $\beta$-1,4-glycosidic linkages of agarose/agar to give NA4 and NA6 [31-35]. $\beta$-agarases isolated from Stenotrophomonas sp. NTa and Agarivorans sp. JA-1 in Bacillus subtilis degraded agarose/agar to yield NA2, NA4 and NA6 as the predominant products [36,37]. Agarivorans albus OAY02 could secrete two $\beta$-agarases, among them, one $\beta$-agarase could cleave agarose into NA2 and NA4, the other $\beta$-agarase hydrolyzed agarose to NA2, NA4, NA6 and NA8 [38]. $\beta$-agarase from marine Pseudoalteromonas sp. CY24 could degrade agarose to NA8 and NA10 [39]. $\beta$-Agarase from marine bacteria can degrade agarose to NAOS with different DP; however, up to now, it has not been reported that $\beta$-agarase could degrade agarose/agar to obtain NAOS with desired DP by controlling the enzymolysis time.

Developing methods for separation and purification of NAOS is also very important for obtaining purified NAOS. Size-sieving based on gel-permeation chromatography (GPC) and high-performance anion exchange chromatography (HPAEC) are commonly used methods for the separation of polysaccharides and oligosaccharides [6,40-43]. Toyopearl HW-40S was used to purify NA4 [40]. It was reported that NAOS with DP of 2, 4, and 6 could be separated and purified by Bio-Gel P2 [42,43] and NA4, NA6, NA8, NA10 and NA12 could be separated by two chromatography steps of consecutive Bio-Gel P-6 chromatography [42]. Sephadex G-10 combined with G-25 was employed to purify AOS [6,41]. The SEC-HPLC and $\mathrm{NH}_{2}$-HPLC systems were used to isolate and purify NAOS and 
AOS [44]. A HPAEC system equipped with a semi-preparative CarboPac ${ }^{\mathrm{TM}}$ PA100 column was applied to prepare NAOS and AOS from DP 2 to DP 22 with product yields and purity of no more than $17.2 \%$ and $77.7 \%$, respectively [45]. However, these methods are complicated, time-consuming, and rely on instrumentation; furthermore, the product yield and purity of obtained oligosaccharides are not high enough for further study. Therefore, to deeply understand the bioactivities and the mechanism of NOAS [9], a simple method for the preparation of NAOS with various DPs is urgently required.

In the present study, a simple method of obtaining NAOS with desired DP was established by controlling the enzymolysis time of $\beta$-agarase. Furthermore, a gel filtration chromatography method was developed for the purification of each NAOS with different DP in high quality and quantity, making it possible to further study their bioactivities.

\section{Materials and Methods}

\subsection{Strains and Reagents}

NA2, NA4, NA6, NA8, NA10 and NA12 were used as standards and were purchased from Qingdao Bozhihui Biological Technology Co., Ltd. (Qingdao, China). Acetonitrile was purchased from Sigma-Aldrich (St. Louis, MO, USA). All the other reagents were commercially available and were of analytical grade.

The culture and fermentation condition of Vibrio natriegens was the same as reported in our previous work [46]. The obtained $\beta$-agarase was purified from the fermentation liquor by salting-out with ammonium sulfate, followed by dialysis, ion exchange chromatography and gel filtration. The definition of enzyme activity: under specified conditions, $1 \mathrm{mg}$ crude enzyme produces $1 \mu \mathrm{g}$ reducing sugar for $1 \mathrm{~min}$.

\subsection{Optimization of Enzymatic Hydrolysis Condition}

The enzymatic hydrolysis condition, including reaction temperature $(30,35,40,45,50,55$ and $\left.60^{\circ} \mathrm{C}\right), \mathrm{pH}(6.0,6.5,7.0,7.5,8.0,8.5$ and 9.0), reaction time $(1,5,10,15,20,25$ and $30 \mathrm{~h})$, substrate concentration $(0.1,0.2,0.3,0.4,0.5,0.6$ and $0.7 \%)$ and enzyme amounts $(20,40,60,80,100,120$ and $140 \mathrm{U} / \mathrm{g}$ ) were all optimized. All hydrolysis reactions were conducted in triplicate.

\subsection{Preparation of NAOS Products with Different Enzymolysis Time}

$3 \mathrm{~g}$ agar was completely dissolved in $1 \mathrm{~L}$ of $0.1 \mathrm{M}$ Tris- $\mathrm{HCl}$ solution by heating and then cooled to $45^{\circ} \mathrm{C}$. Subsequently, the solution was treated with the $\beta$-agarase for $4 \mathrm{~h}, 6 \mathrm{~h}, 8 \mathrm{~h}, 10 \mathrm{~h}$ or $12 \mathrm{~h}$ to obtain products $\mathrm{A}, \mathrm{B}, \mathrm{C}, \mathrm{D}$ and $\mathrm{E}$, respectively. After inactivation by incubation in a boiling water bath for $15 \mathrm{~min}$ and centrifugation for $30 \mathrm{~min}(12,000 \mathrm{rpm})$, the insoluble agar was removed and the NAOS in the supernatant was filtered with a $0.22 \mu \mathrm{m}$ membrane (Millipore, Cork, Ireland). The crude products resulting from the different enzymolysis times were finally obtained by evaporation, concentration and lyophilization and stored at $-20^{\circ} \mathrm{C}$ until needed. Each product was measured in triplicate.

\subsection{Analysis of NAOS Products by HPLC-ELSD}

The NAOS products were analyzed by an HPLC-ELSD system which consisted of a Waters e2695 HPLC system (Waters, Milford, MA, USA) equipped with an evaporative light scattering detector (Waters 2424, USA). Separation was performed on an Asahipak $\mathrm{NH}_{2} \mathrm{P}-504 \mathrm{E}$ multi-mode analytical column $(250 \mathrm{~mm} \times 4.6 \mathrm{~mm}, 5 \mu \mathrm{m})$ with the column temperature set at $30^{\circ} \mathrm{C}$. Isocratic elution was conducted with acetonitrile-water (65:35) as the mobile phase with a flow rate of $1 \mathrm{~mL} / \mathrm{min}$. The injection volume was set at $10 \mu \mathrm{L}$ and the detector nebulizer temperature was $75^{\circ} \mathrm{C}$.

\subsection{Purification of NAOS}

For the purification of NAOS, $1 \mathrm{~g}$ of crude NAOS product powder was resuspended in $200 \mathrm{~mL}$ distilled water, followed by the addition of $10 \mathrm{~g}$ of activated carbon. The mixture was stirred for $2 \mathrm{~h}$ 
and then the NAOS were washed with 30\% ethanol solution, and ethanol was removed by evaporation. Then the remainder was freeze-dried and detected.

GPC was applied to separate the NAOS. A sample of $250 \mathrm{mg}$ of products A was resuspended in $1 \mathrm{~mL}$ of $\mathrm{NH}_{4} \mathrm{HCO}_{3}(0.1 \mathrm{M})$, and the solutions were loaded onto the Bio-Gel P2 column $(1.8 \times 150 \mathrm{~cm}$, Bio-Rad Laboratories, Hercules, CA, USA). $\mathrm{NH}_{4} \mathrm{HCO}_{3}$ solution was used as the eluent at a flow rate of $0.4 \mathrm{~mL} / \mathrm{min}$ and a tube of $4 \mathrm{~mL}$ were collected. Then the collected fractions were detected by TLC on a Silica Gel 60 plate (Merck, Darmstadt, Germany) and developed with a solvent of isopropanol/water/ammonium hydroxide (30:15:2, v/v/v). After being sprayed by anisaldehyde and heated for $10 \mathrm{~min}$, the products could be visualized as spots and could merge the same components.

\subsection{Identification of NAOS}

The structure and the molecular mass of the isolated NAOS were elucidated by FTIR, ESI-TOF-MS and NMR. The FTIR spectra were obtained on an FTIR-84 spectrophotometer (Shimadzu, Japan) on $\mathrm{KBr}$ pellets; the NAOS were dried at $105^{\circ} \mathrm{C}$ for $2 \mathrm{~h}$ prior to recordings. Scans were performed over the range of $4000-400 \mathrm{~cm}^{-1}$ with a resolution of $4 \mathrm{~cm}^{-1}$ for 32 scans. ESI-TOF-MS analysis was carried out on a Q Exactive Hybrid Quadrupole Orbitrap mass spectrometer (Thermo, Bremen, Germany) coupled with an ESI source in positive ion mode. The recorded mass range was $m / z$ 200-2000. ${ }^{1} \mathrm{H}-\mathrm{NMR}$ and ${ }^{13} \mathrm{C}$-NMR spectra were measured in $\mathrm{D}_{2} \mathrm{O}$ on an Avance 500 spectrometer (Bruker, Avance III, Switzerland, $500 \mathrm{MHz}{ }^{1} \mathrm{H}, 125 \mathrm{MHz}{ }^{13} \mathrm{C}$ ) at room temperature and $\mathrm{C}_{3} \mathrm{D}_{6} \mathrm{O}$ was added as an internal standard, its chemical shifts were reported at $\delta=2.05 \mathrm{ppm}$ for ${ }^{1} \mathrm{H}-\mathrm{NMR}, \delta=29.84 \mathrm{ppm}$ for ${ }^{13} \mathrm{C}-\mathrm{NMR}$.

\section{Results and Discussion}

\subsection{Optimization of Hydrolysis Parameters by Single Factor Experiments}

Single factor experiments were carried out to optimize the enzymatic hydrolysis process. Figure $1 \mathrm{~A}$ depicts the influence of temperature on the yield of reducing sugar. Temperature is an important factor in the enzymatic hydrolysis process [22]. Within a certain temperature range, the increased temperature is beneficial to the enzymatic reaction. As shown in Figure $2 \mathrm{a}$, the yield of reducing sugar was increased with the elevation of temperature and it reached a maximum of $45.2 \%$ at $45^{\circ} \mathrm{C}$, after that the yield was decreased significantly with increased temperature. Therefore, the optimal temperature was determined to be $45^{\circ} \mathrm{C}$. The $\mathrm{pH}$ is another vital parameter in the enzymatic hydrolysis process because enzyme activity is greatly affected by the $\mathrm{pH}$ [28]. Generally, an enzyme can maintain high enzyme activity at a suitable $\mathrm{pH}$. As shown in Figure $2 \mathrm{~b}$, the yield of reducing sugar was increased with the increase of $\mathrm{pH}$ from 6.0 to 8.5 , the largest yield of reducing sugar was $42.7 \%$ at $\mathrm{pH} 8.5$. Above $\mathrm{pH} 8.5$, the yield was decreased, which may be attributed to the inhibition of the $\beta$-agarase activity. As for the substrate concentration, low substrate concentration leads to low enzyme utilization; however, a too high substrate concentration hinders the diffusion of molecules and thereby reduces the enzymatic reaction rate. As shown in Figure 2c, when the substrate concentration was set to $0.3 \%$, the yield of reducing sugar increased to $43.3 \%$. In addition, not only the enzyme amount but also enzymolysis time has prominent effects on the yield of reducing sugar $[47,48]$. The enzyme amounts were also investigated in the present study and using $100 \mathrm{U} / \mathrm{g}$ turned out to be optimal, affording a $42.4 \%$ yield of reducing sugar (Figure 2d). Furthermore, the yield of reducing sugar was not increased by the addition of more enzymes. Figure 2e indicated that the yield of reducing sugar increased with the extension of enzymolysis time up to $20 \mathrm{~h}$. When the enzymolysis time was $20 \mathrm{~h}$, the reducing sugar yield was highest at $43.3 \%$, and increasing the enzymolysis time further did not increase the yield. Therefore, the optimized conditions were determined as follows: a temperature of $45^{\circ} \mathrm{C}$, a pH of 8.5 , a substrate concentration of $0.3 \%$, an enzyme amount of $100 \mathrm{U} / \mathrm{g}$ and an enzymolysis time of $20 \mathrm{~h}$. 

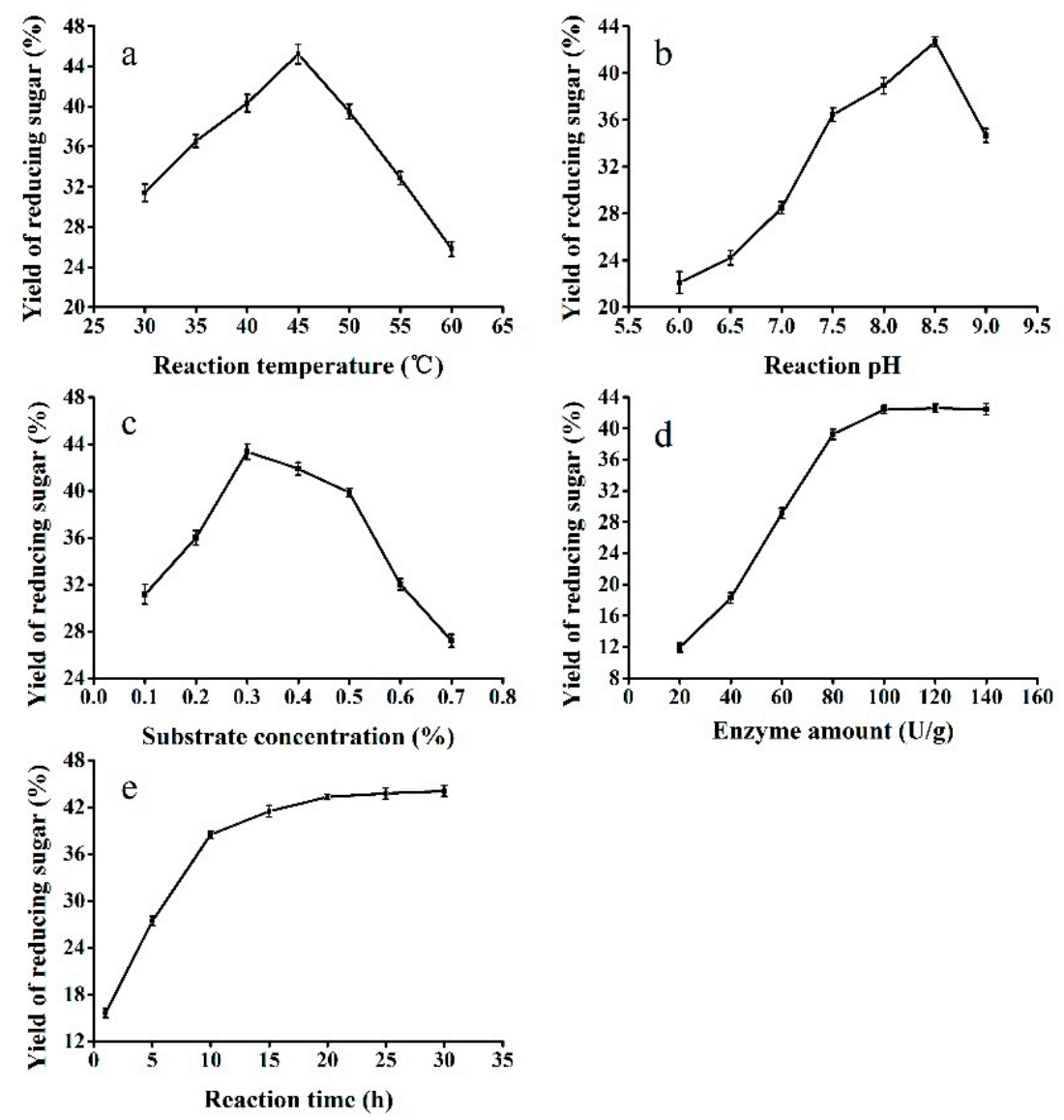

Figure 2. Effects of enzymolysis condition on reducing sugar yield.

\subsection{Preparation of $N A O S$ with Different $D P$}

The $\beta$-agarase obtained from different strains degrade agar to gain the NAOS with different DP $[28,32,36,37]$. It has been reported that the immobilized $\beta$-agarase could prepare NAOS with different DP by controlling the enzyme hydrolysis time [24]. But, the regular changes of NAOS with different DP at different enzymolysis time were found in the present study (Figure 3), which was not previously reported. The enzymolysis products were determined by HPLC-ELSD by comparing with authentic standard substances, and the content of each oligosaccharide was calculated from the regression equations, as shown in Figure 2, Tables 1 and 2. The enzymolysis products were found to be composed of NA2, NA4, NA6, NA8, NA10 and NA12 with yields of 5.0, 38.9, 18.1, 16.8, 13.8 and $2.5 \mathrm{mg} / 100 \mathrm{mg}$, respectively after the agar was hydrolyzed by $\beta$-agarase for $4 \mathrm{~h}$. When the hydrolysis time was 6 h, NA12 was completely hydrolyzed and the products obtained were NA2, NA4, NA6, NA8, and NA10 with yields of $6.0,52.7,15.2,13.7$, and $11 \mathrm{mg} / 100 \mathrm{mg}$, respectively. As the hydrolysis time was extended to $8 \mathrm{~h}$, NA10 was not detected in the product mixture and the yields of NA2, NA4, NA6 and NA8 were 9.3, 59.5, 13.7 and $11.7 \mathrm{mg} / 100 \mathrm{mg}$, respectively. With the extension of the hydrolysis time, the DP of NAOS obtained were decreased. When the hydrolysis time was $10 \mathrm{~h}$, the product mixture consisted of NA2, NA4, and NA6 with yields of 13.8, 68.4 and $9.6 \mathrm{mg} / 100 \mathrm{mg}$, respectively. Once the hydrolysis time reached $12 \mathrm{~h}$, only NA4 and NA2 were left in the product mixture with the yields of $21.6 \mathrm{mg} / 100 \mathrm{mg}$ and $71.1 \mathrm{mg} / 100 \mathrm{mg}$, respectively. Beyond $12 \mathrm{~h}$, the product components were no longer changed with the extension of time. 


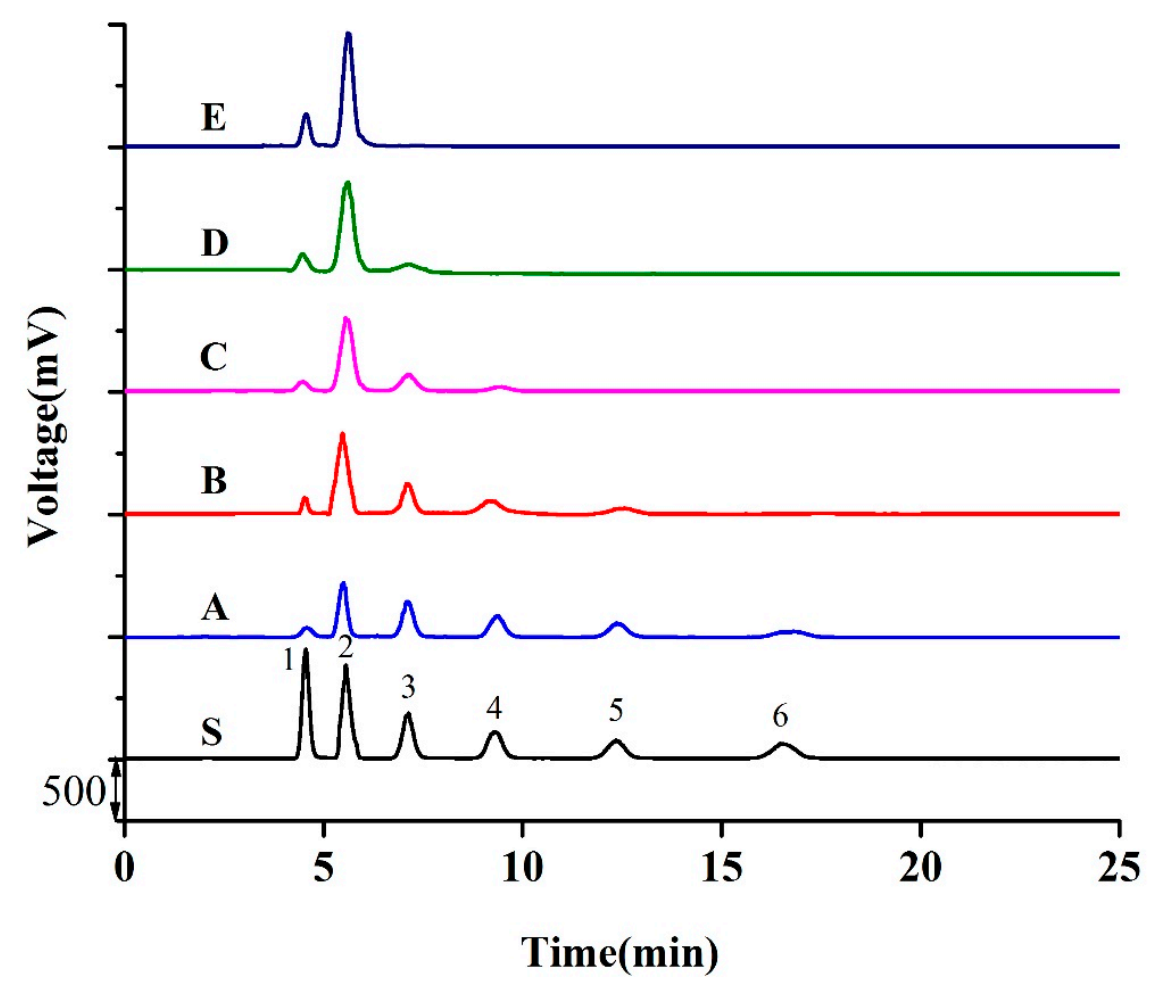

Figure 3. Analysis of enzymatic hydrolysates with different enzymolysis times, S-NAOS standards, 1-NA2, 2-NA4, 3-NA6, 4-NA8, 5-NA10, 6-NA12; A 4 h, B 6 h, C 8 h, D 10 h, E 12 h.

Table 1. The regression equations of NAOS.

\begin{tabular}{ccc}
\hline Oligosaccharide & \multicolumn{1}{c}{ Equation } & $\mathbf{R}^{\mathbf{2}}$ \\
\hline NA2 & $\mathrm{y}=6.29305 \mathrm{x}-2.21022$ & 0.992 \\
NA4 & $\mathrm{y}=6.05888 \mathrm{x}-3.18131$ & 0.996 \\
NA6 & $\mathrm{y}=5.54881 \mathrm{x}-3.71928$ & 0.997 \\
NA8 & $\mathrm{y}=4.85490 \mathrm{x}-4.42057$ & 0.996 \\
NA10 & $\mathrm{y}=4.48493 \mathrm{x}-3.88547$ & 0.994 \\
NA12 & $\mathrm{y}=4.25971 \mathrm{x}-3.75222$ & 0.992 \\
\hline x: the concentration of NAOS $(\mathrm{mg} / \mathrm{mL}), \mathrm{y}:$ peak area $\times 10^{-6}$.
\end{tabular}

Table 2. The percentage of monomers at different hydrolysis times (mg/100 mg).

\begin{tabular}{cccccc}
\hline & A & B & C & D & E \\
\hline NA2 & 5.0 & 6.0 & 9.3 & 13.8 & 21.6 \\
NA4 & 38.9 & 52.7 & 59.5 & 68.4 & 71.1 \\
NA6 & 18.1 & 15.2 & 13.7 & 9.6 & nd \\
NA8 & 16.8 & 13.7 & 11.7 & nd & nd \\
NA10 & 13.8 & 11.0 & nd & nd & nd \\
NA12 & 2.5 & nd & nd & nd & nd \\
\hline
\end{tabular}

A, B, C, D and E are the products that resulted from agar upon treatment with $\beta$-agarase for $4 \mathrm{~h}, 6 \mathrm{~h}, 8 \mathrm{~h}, 10 \mathrm{~h}$ and $12 \mathrm{~h}$, respectively. nd: the monomers were not detected.

At present, there are increasing numbers of reports on the preparation of NAOS by the enzymatic method, and agarase is mainly derived from the secretions of marine bacteria. Frequently, $\beta$-agarase is found to degrade agar to generate NA2, NA4, or NA6 as the main products. DagA secreted $\beta$-agarase hydrolyzes agar to gain NA2, NA4 and NA6 [49]. $\beta$-agarase from Stenotrophomonas sp. NTa degrades agar to yield NA2, NA4 and NA6 as the predominant products with a small amount of 3,6 -anhydro- $\alpha$-L-galactose; notably the products did not change with the change of the hydrolysis time [37]. At the same time, the composition of the agarolytic product did not change over time due 
to some $\beta$-agarase, which included four even-numbered NAOS with DP of $2-8$, and the amount of NA4 was greater than for the others [27]. However, these methods found in the literature were used in preparing NAOs mainly with DP of no more than eight $[27,37,49]$. Interestingly, we found in our study that the DP of the NAOS was reduced regularly with increased enzymolysis time, and the final product was composed of NA4 and NA2. Therefore, desired NOAS with different DP could be obtained by controlling the enzymolysis time, which may be beneficial to the further studies on NAOS.

\subsection{Separation of NAOS}

Separation and purification of NAOS was carried out using a Bio-Gel P2 column and detected by TLC, and the results are shown in Figure 4. For product A, fractions 18 to 22 contained NA12 with a yield of $3.2 \%$; fractions 24 to 27 contained NA10 with a yield of $4.2 \%$; fractions 30 to 35 contained NA8 with a yield of $7.5 \%$; fractions 37 to 40 contained NA6 with a yield of $10.2 \%$; fractions 44 to 56 contained NA4 with a yield of $35.8 \%$; and fractions 61 to 64 contained NA2 with a yield of $23.2 \%$. After detection by HPLC-ELSD, the purity of NA2, NA4, NA6, NA8, NA10 and NA12 were $99.3 \%, 98.9 \%$, 98.0\%, 97.6\%, 97.3\% and 97.4\%, respectively (Figure 5).

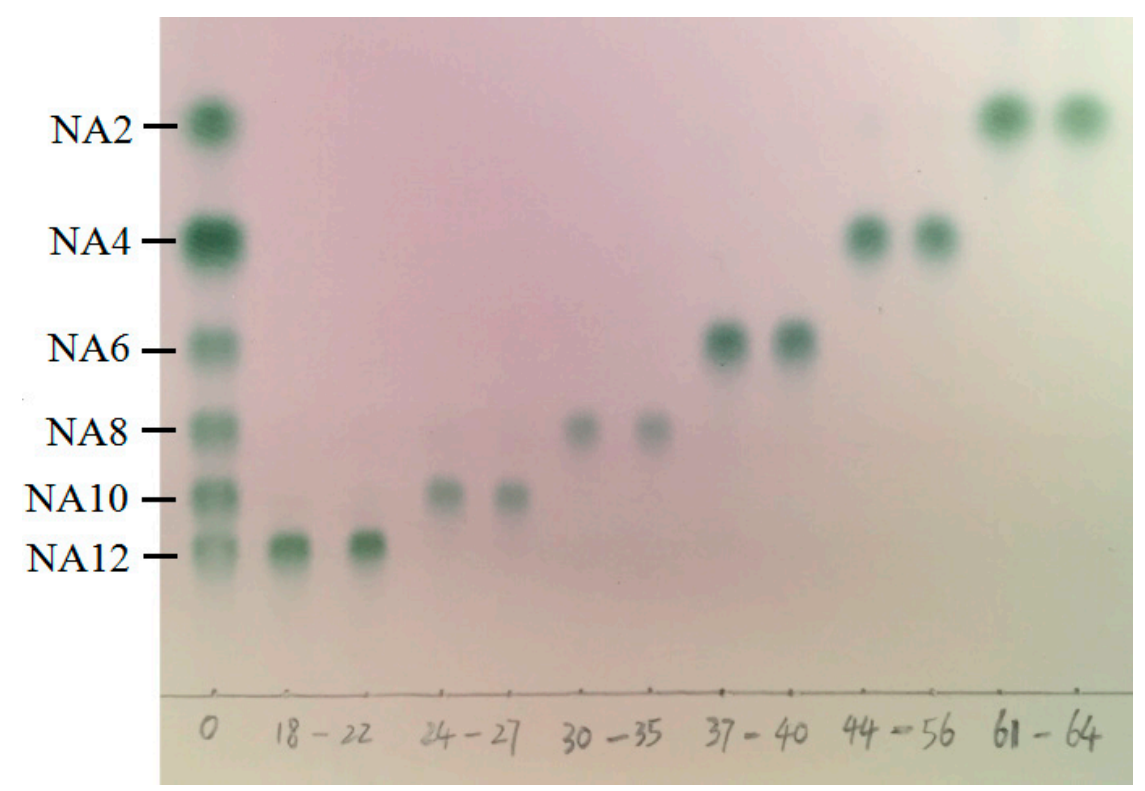

Figure 4. TLC analysis of purified NAOS. The ladder of NAOS with different DP (2-12); S: NAOS standards; Fractions 18-22: NA12, Fractions 24-27: NA10, Fractions 30-35: NA8, Fractions 37-40: NA6, Fractions 44-56: NA4, Fractions 61-64: NA2.

GPC and HPAEC are commonly used methods for the separation and purification of NAOS, and Bio-Gel P-2 and Bio-Gel P-6 are frequently applied to purify NAOS [6,40-45]. However, these two separations methods are usually combined to isolate NAOS with diverse DP. Notably, in the present study, one chromatographic step using Bio-Gel P-2 column chromatography allowed us to obtain NAOS of DP2-12 with purities of greater than $97 \%$, suggesting that it is a simple method for the preparation of NAOS. 


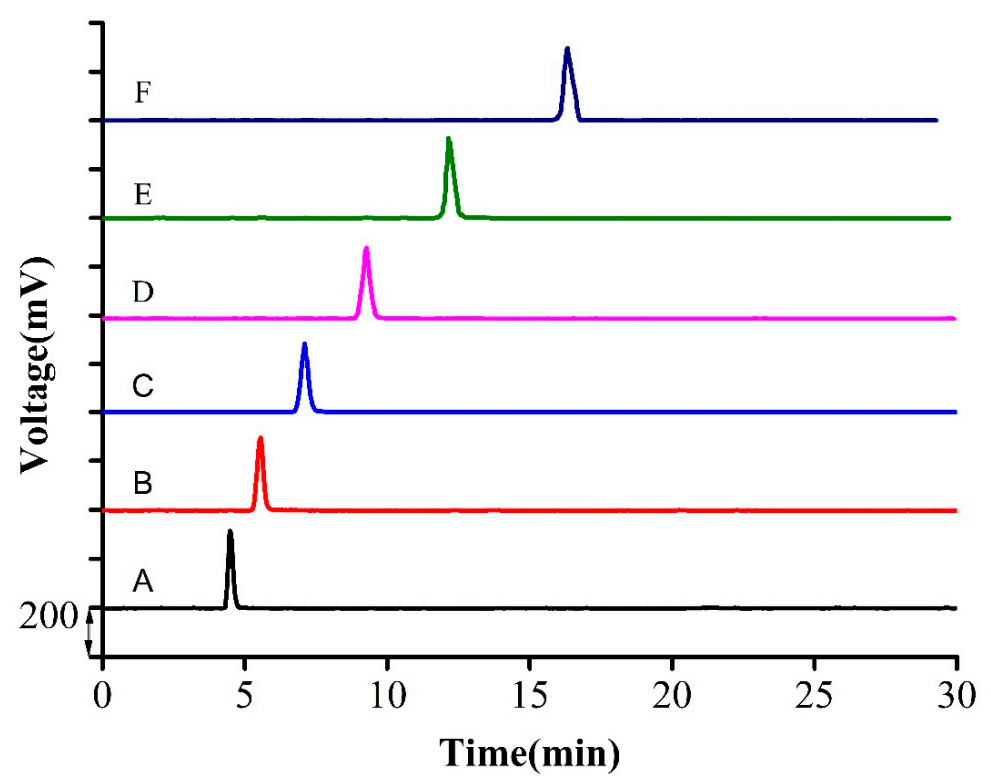

Figure 5. High liquid chromatograms of purified products.

\subsection{Characterization of NAOS}

The structures and the molecular mass of the purified NAOS were determined by FTIR and MS analysis. Figure 6 shows the results of the FTIR analyses. In all six obtained oligosaccharides, the disappearance of an absorption band around $1260 \mathrm{~cm}^{-1}$ indicated the elimination of a sulfate group in the degradation process. There was a broad absorption band around $3400 \mathrm{~cm}^{-1}$, which may be assigned to hydroxyl groups. The region around $2950 \mathrm{~cm}^{-1}$ and $2900 \mathrm{~cm}^{-1}$ were assigned as $\mathrm{C}-\mathrm{H}$ groups. The band around $1640 \mathrm{~cm}^{-1}$ suggested the existence of a $\mathrm{C}-\mathrm{C}$ sugar ring. The fingerprint region, including many FTIR absorptions of specific characteristic bonds, was a region of lower wave numbers. There was an absorption band around $1159 \mathrm{~cm}^{-1}$ which was assigned as the stretch vibration of $\mathrm{C}-\mathrm{O}$ within C-O-H. Absorption bands appeared at $1072 \mathrm{~cm}^{-1}$, indicating the presence of $\mathrm{C}-\mathrm{O}$ within $\mathrm{C}-\mathrm{O}-\mathrm{C}$ bond. A well-defined peak was shown at about $930 \mathrm{~cm}^{-1}$ corresponding to 3,6-anydro-D-galactose.

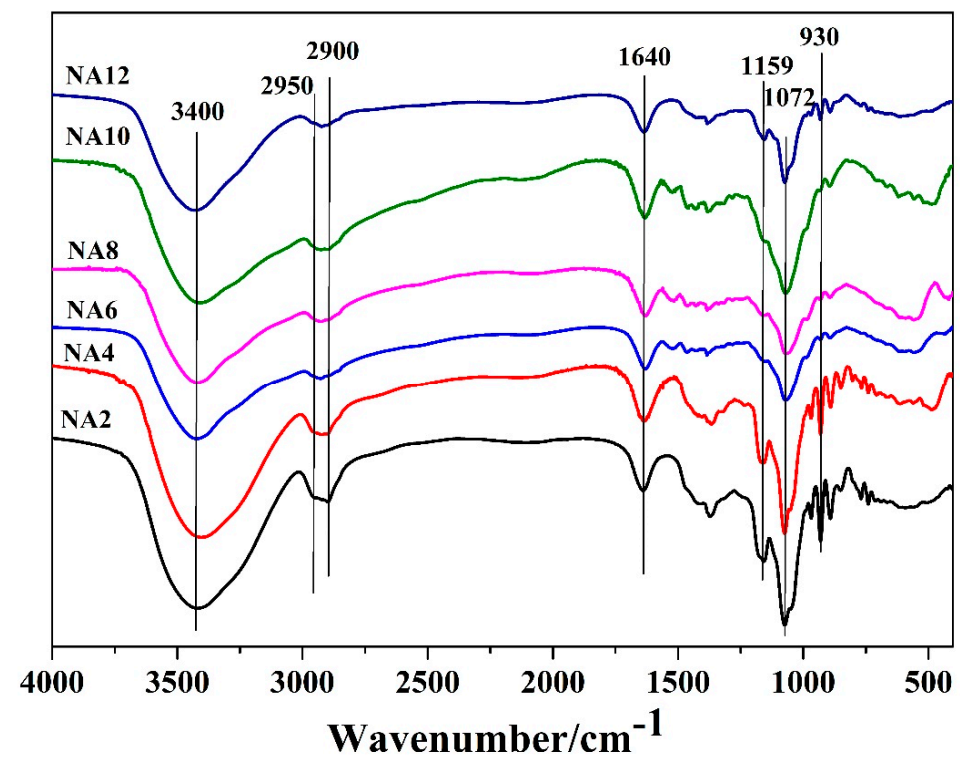

Figure 6. FTIR spectrum of NAOS. 
The ESI-TOF-MS analysis results are displayed in Table 3, confirming that the purified oligosaccharides were NA2, NA4, NA6, NA8, NA10 and NA12. The NA4 is shown in Figure 7 and other monomers were in Figures S1, S2 and S3.

Table 3. The ESI-TOF-MS analysis of the purified products.

\begin{tabular}{ccc}
\hline Purified Products & $\begin{array}{c}\text { MS Signals }(\boldsymbol{m} / \mathbf{z}) \\
{[\mathbf{M}+\mathbf{N a}]^{+}}\end{array}$ & Calculated Molecular Weights \\
\hline NA2 & 347.0949 & 347.0954 \\
NA4 & 653.1886 & 653.1905 \\
NA6 & 959.2866 & 959.2856 \\
NA8 & 1265.3752 & 1265.3807 \\
NA10 & 1571.4752 & 1571.4757 \\
NA12 & 1877.5751 & 1877.5708 \\
\hline
\end{tabular}

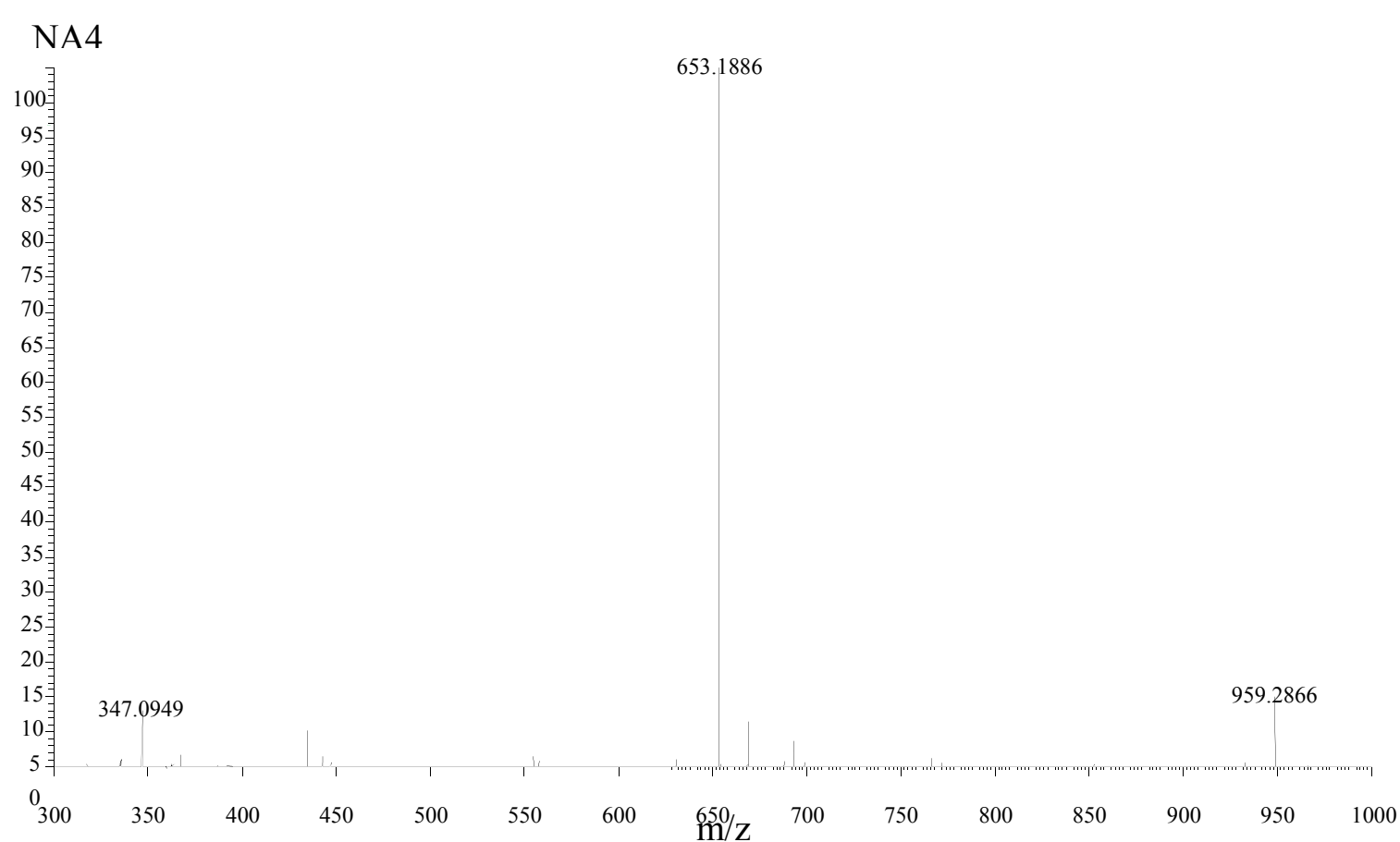

Figure 7. The ESIMS spectra of NA4.

The structural information of six monomers was determined by ${ }^{1} \mathrm{H}-\mathrm{NMR}$ and ${ }^{13} \mathrm{C}-\mathrm{NMR}$ spectroscopy. Assignments of ${ }^{1} \mathrm{H}-\mathrm{NMR}$ and ${ }^{13} \mathrm{C}-\mathrm{NMR}$ spectroscopy were determined by comparison to literature values, and the interpretation of these signals was shown in Figure 8 and Table $4[1,43,44]$. The spectra indicated the presence of twelve major anomeric carbon signals ( $G$ and $A$ ), which we assigned as the major repeating unit of NA2, and the signals (Gnr and Anr) were the residues towards the nonreducing end of the NAOS. Resonances at around 96.6 and $92.6 \mathrm{ppm}$ were characteristic of $\beta$ and $\alpha$ anomeric form of galactose residues at the reducing end of the NAOS [42,50], respectively. The ${ }^{13} \mathrm{C}-\mathrm{NMR}$ spectrum of NA4 is shown in Figure $9 .{ }^{1} \mathrm{H}-\mathrm{NMR}$ and ${ }^{13} \mathrm{C}-\mathrm{NMR}$ of other monomers are shown in Figure S2, respectively. 


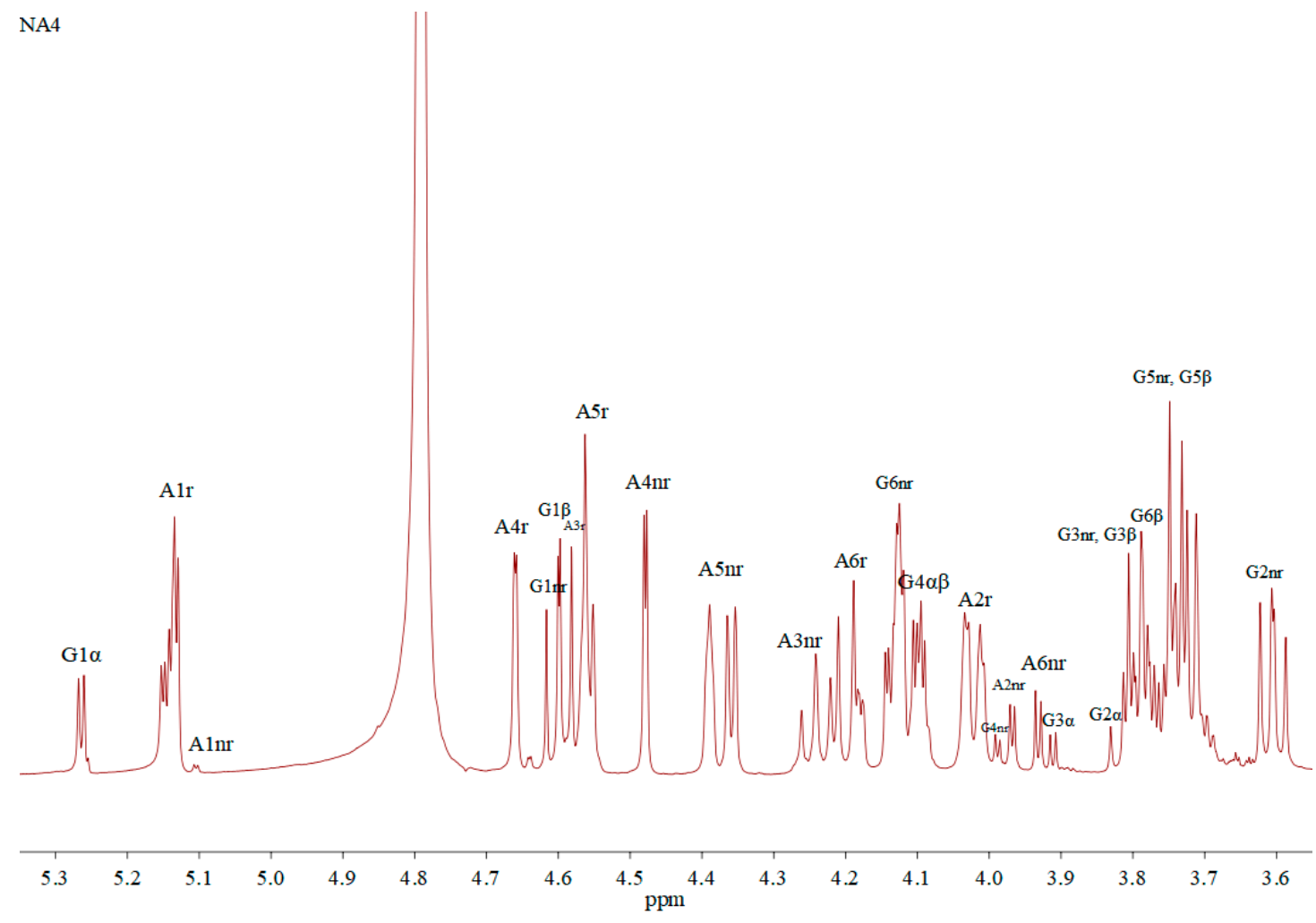

Figure 8. ${ }^{1} \mathrm{H}$ NMR spectra of NA4, Peak labels: A, 3,6 anhydrogalactose; G, galactose; $\mathrm{nr}$ and $\mathrm{r}$ refer to the non-reducing and reducing ends; $\alpha, \beta$ refer to positions of protons on reducing ends; numbers from 1 to 6 refer to place of protons.

NA4

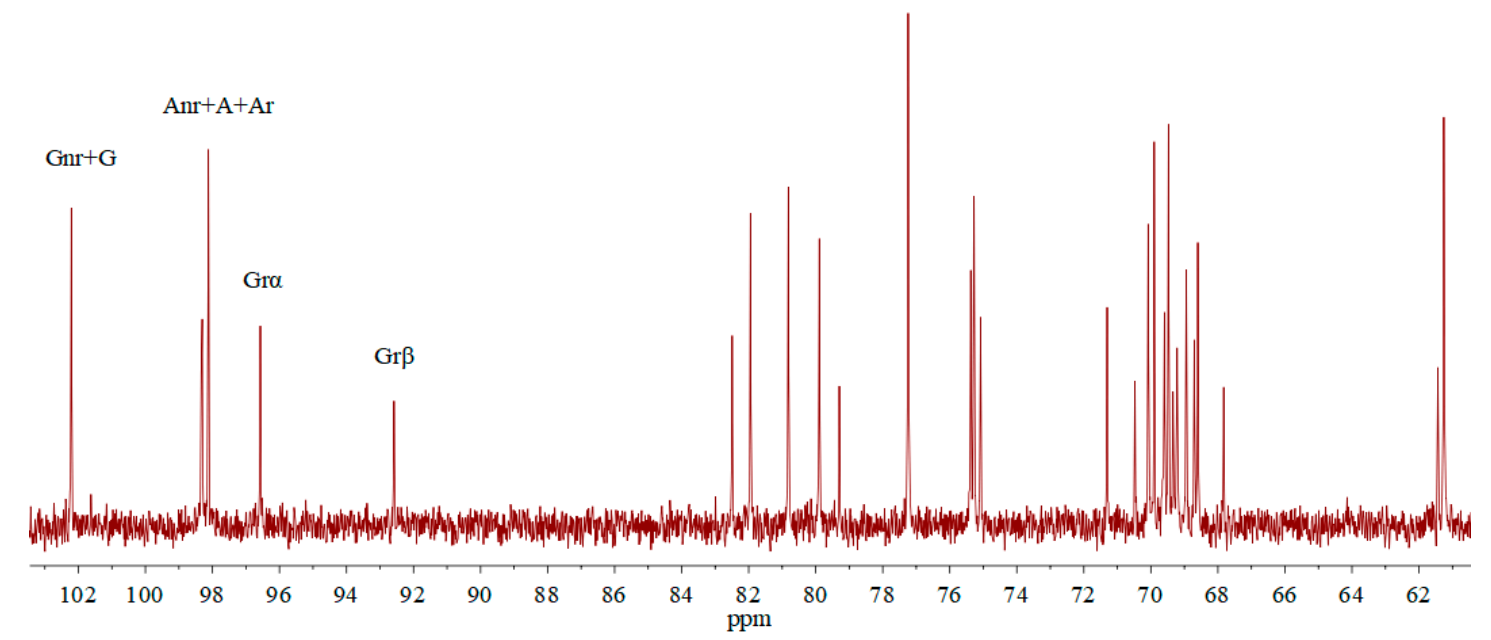

Figure 9. ${ }^{13} \mathrm{C}$ NMR spectra of NA4. 
Table 4. Chemical shift assignments for ${ }^{13} \mathrm{C}-\mathrm{NMR}$ spectra of NAOS.

\begin{tabular}{ccccccc}
\hline Unit & C1 & C2 & C3 & C4 & C5 & C6 \\
\hline Gnr & 102.2 & 69.9 & 82.0 & 67.8 & 75.1 & 61.3 \\
Gr $\beta$ & 96.6 & 69.9 & 82.5 & 68.6 & 75.1 & 61.3 \\
Gr $\alpha$ & 92.6 & 67.8 & 79.9 & 69.2 & 69.9 & 61.4 \\
Anr & 98.3 & 69.4 & 80.8 & 69.6 & 77.3 & 68.7 \\
Ar $\alpha$ & 98.1 & 69.5 & 79.9 & 77.3 & 75.3 & 69.0 \\
\hline
\end{tabular}

\section{Conclusions}

In summary, the present study has developed a feasible approach for the preparation of desired NAOS with different DP by regulating the enzymolysis time of $\beta$-agarase. Furthermore, the NAOS of diverse DP were simply isolated by Bio-gel P2 column chromatography with purities greater than $97 \%$, which may be useful for further evaluating their bioactivity potential.

Supplementary Materials: The following are available online at http://www.mdpi.com/2227-9717/7/5/267/s1, Figure S1: The ESIMS spectra of NA2, NA6, NA8, NA10 and NA12, Figure S2: ${ }^{1} \mathrm{H}$ NMR spectra of NA2, NA6, NA8, NA10 and NA12, Figure S3: ${ }^{13}$ C-NMRspectra of NA2, NA6, NA8, NA10 and NA12.

Author Contributions: Conceptualization, Y.Y. and M.X.; methodology, F.L.; software, Y.Y.; validation, J.Y., Y.H and Y.Y.; resources, M.X.; writing-original draft preparation, F.L.; writing-review and editing, Y.Y. and M.X.; supervision, Y.Y.; project administration, Y.H. and X.M.; funding acquisition, M.X.

Funding: This research was funded by the Public Science and Technology Research Funs Projects of Ocean, grant numbers 20130515-2, 201505026-5, and the Quanzhou Science and Technology Plan Project, grant number $2015 Z 140$.

Acknowledgments: This work was supported by the Public Science and Technology Research Funs Projects of Ocean [grant numbers 20130515-2, 201505026-5]; Subsidized Project for Postgraduates' Innovative Fund in Scientific Research of Huaqiao University and Quanzhou Science and Technology Plan Project [grant number 2015Z140]. We thank James Murray, PhD, from Edanz Group (www.edanzediting.com/ac) for editing a draft of this manuscript.

Conflicts of Interest: The authors declare no conflict of interest.

\section{References}

1. Hamer, G.K.; Bhattacharjee, S.S.; Yaphe, W. Analysis of the enzymlc hydmlysls products of agahose by C-NMR. Carbohydr. Res. 1977, 54, C7-C10. [CrossRef]

2. Jensen, A. Present and future needs for algae and algal products. Hydrobiologia 1993, 260-261, 15-23. [CrossRef]

3. Chi, W.J.; Chang, Y.K.; Hong, S.K. Agar degradation by microorganisms and agar-degrading enzymes. Appl. Microbiol. Biotechnol. 2012, 94, 917-930. [CrossRef]

4. Chen, H.M.; Zheng, L.; Yan, X.J. The preparation and bioactivity research of agaro-oligosaccharides. Food Technol. Biotech. 2005, 43, 29-36.

5. Chen, H.M.; Yan, X.J. Antioxidant activities of agaro-oligosaccharides with different degrees of polymerization in cell-based system. Biochim. Biophys. Acta 2005, 1722, 103-111. [CrossRef]

6. Wu, S.C.; Wen, T.N.; Pan, C.L. Algal-oligosaccharide-lysates prepared by two bacterial agarases stepwise hydrolyzed and their anti-oxidative properties. Fish. Sci. 2005, 71, 1149-1159. [CrossRef]

7. Chen, H.; Yan, X.; Zhu, P.; Lin, J. Antioxidant activity and hepatoprotective potential of agaro-oligosaccharides in vitro and in vivo. Nutr. J. 2006, 5, 31-42. [CrossRef] [PubMed]

8. Kang, O.L.; Ghani, M.; Hassan, O.; Rahmati, S.; Ramli, N. Novel agaro-oligosaccharide production through enzymatic hydrolysis: Physicochemical properties and antioxidant activities. Food Hydrocolloids 2014, 42, 304-308. [CrossRef]

9. Xu, S.Y.; Huang, X.; Cheong, K.L. Recent advances in marine algae polysaccharides: Isolation, structure, and activities. Mar. Drugs 2017, 15, 388. [CrossRef] [PubMed]

10. Higashimura, Y.; Naito, Y.; Takagi, T.; Uchiyama, K.; Mizushima, K.; Ushiroda, C.; Ohnogi, H.; Kudo, Y.; Yasui, M.; Inui, S.; et al. Protective effect of agaro-oligosaccharides on gut dysbiosis and colon tumorigenesis in high-fat diet-fed mice. Am. J. Physiol-Gastr. Liver Physiol. 2016, 310, G367-G375. [CrossRef] 
11. Higashimura, Y.; Baba, Y.; Inoue, R.; Takagi, T.; Mizushima, K.; Ohnogi, H.; Honda, A.; Matsuzaki, Y.; Naito, Y. Agaro-oligosaccharides regulate gut microbiota and adipose tissue accumulation in mice. J. Nutr. Sci. Vitaminol. 2017, 63, 269-276. [CrossRef] [PubMed]

12. Enoki, T.; Tanabe, M.; Shimomura, M.; Ohnogi, H. Induction mechanism of heme oxygenase-1 and anti-inflammatory activity by agaro-oligosaccharides. Nippon Shokuhin Kogyo Gakkaishi 2010, 57, 157-162. [CrossRef]

13. Enoki, T.; Tominaga, T.; Takashima, F.; Ohnogi, H.; Sagawa, H.; Kato, I. Anti-tumor-promoting activities of agaro-oligosaccharides on two-stage mouse skin carcinogenesis. Biol. Pharm. Bull. 2012, 35, 1145-1149. [CrossRef] [PubMed]

14. Higashimura, Y.; Naito, Y.; Takagi, T.; Tanimura, Y.; Mizushima, K.; Harusato, A.; Fukui, A.; Yoriki, H.; Handa, O.; Ohnogi, H.; et al. Preventive effect of agaro-oligosaccharides on non-steroidal anti-inflammatory drug-induced small intestinal injury in mice. J. Gastroen. Hepatol. 2014, 29, 310-317. [CrossRef]

15. Kobayashi, R.; Takisada, M.; Suzuki, T.; Kirimuraab, K.; Usamiab, S. Neoagarobiose as a novel moisturizer with whitening effect. Biosci. Biotechnol. Biochem. 1997, 61, 162-163. [CrossRef] [PubMed]

16. Kim, J.H.; Yun, E.J.; Yu, S.; Kim, K.H.; Kang, N.J. Different levels of skin whitening activity among 3,6-Anhydro-1-galactose, Agarooligosaccharides, and Neoagarooligosaccharides. Mar. Drugs 2017, 15, 321. [CrossRef] [PubMed]

17. Potin, P.; Richard, C.; Rochas, C.; Kloareg, B. Purification and characterization of the $\alpha$-agarase from Alteromonas agarlyticus (Cataldi) comb. nov., strain GJ1B. Eur. J. Biochem. 1993, 214, 559-607. [CrossRef]

18. Hassairi, I.; Amar, R.B.; Nonus, M.; Gupta, B.B. Production and separation of $\alpha$-agarase from Altermonas agarlyticus strain GJ1B. Bioresour. Technol. 2001, 79, 47-51. [CrossRef]

19. Ohta, Y.; Hatada, Y.; Miyazaki, M.; Nogi, Y.; Ito, S.; Horikoshi, K. Purification and characterization of a novel alpha-agarase from a Thalassomonas sp. Curr. Microbiol. 2005, 50, 212-216. [CrossRef] [PubMed]

20. Kirimura, K.; Masuda, N.; Iwasaki, Y.; Nakagawa, H.; Kobayashi, R.; Usami, S. Purification and characterization of a novel $\beta$-agarase from an alkalophilic bacterium, Alteromonas sp. E-1. J. Biosci. Bioeng. 1999, 87, 436-441. [CrossRef]

21. Kang, N.Y.; Choi, Y.L.; Cho, Y.S.; Kim, B.K.; Jeon, B.S.; Cha, J.Y.; Kim, C.H.; Lee, Y.C. Cloning, expression and characterization of a $\beta$-agarase gene from a marine bacterium, Pseudomonas sp. SK38. Biotechnol. Lett. 2003, 25, 1165-1170. [CrossRef] [PubMed]

22. Fu, W.; Han, B.; Duan, D.; Liu, W.; Wang, C. Purification and characterization of agarases from a marine bacterium Vibrio sp. F-6. J. Ind. Microbiol. Biotechnol. 2008, 35, 915-922. [CrossRef] [PubMed]

23. Bhattarai, Y.; Kashyap, P.C. Agaro-oligosaccharides: A new frontier in the fight against colon cancer? Am. J. Physiol-Gastr. Liver Physiol. 2016, 310, G335-G336. [CrossRef]

24. Xiao, Q.; Liu, C.; Ni, H.; Zhu, Y.; Jiang, Z.; Xiao, A. beta-Agarase immobilized on tannic acid-modified Fe3O4 nanoparticles for efficient preparation of bioactive neoagaro-oligosaccharide. Food Chem. 2019, 272, 586-595. [CrossRef] [PubMed]

25. Hu, B.; Gong, Q.; Wang, Y.; Ma, Y.; Li, J.; Yu, W. Prebiotic effects of neoagaro-oligosaccharides prepared by enzymatic hydrolysis of agarose. Anaerobe 2006, 12, 260-266. [CrossRef]

26. Wang, W.; Liu, P.; Hao, C.; Wu, L.; Wan, W.; Mao, X. Neoagaro-oligosaccharide monomers inhibit inflammation in LPS-stimulated macrophages through suppression of MAPK and NF-kappaB pathways. Sci. Rep. 2017, 7, 44252. [CrossRef]

27. Xu, X.Q.; Su, B.M.; Xie, J.S.; Li, R.K.; Yang, J.; Lin, J.; Ye, X.Y. Preparation of bioactive neoagaroligosaccharides through hydrolysis of Gracilaria lemaneiformis agar: A comparative study. Food Chem. 2018, 240, 330-337. [CrossRef]

28. Shi, Y.L.; Lu, X.Z.; Yu, W.G. A new $\beta$-agarase from marine bacterium Janthinobacterium sp. SY12. World J. Microbiol. Biotechnol. 2008, 24, 2659-2664. [CrossRef]

29. Fu, X.T.; Lin, H.; Kim, S.M. Purification and characterization of a novel beta-agarase, AgaA34, from Agarivorans albus YKW-34. Appl. Microbiol. Biotechnol. 2008, 78, 265-273. [CrossRef]

30. Sugano, Y.; Terada, I.; Arita, M.; Noma, M.; Matsumoto, T. Purification and characterization of a new agarase from a marine bacterium, Vibrio sp. strain JT0107. Appl. Environ. Micro. 1993, 59, 1549-1554.

31. Su, Q.; Jin, T.; Yu, Y.; Yang, M.; Mou, H.; Li, L. Extracellular expression of a novel beta-agarase from Microbulbifer sp. Q7, isolated from the gut of sea cucumber. AMB Express 2017, 7, 220. [CrossRef] [PubMed] 
32. Wang, J.; Mou, H.; Jiang, X.; Guan, H. Characterization of a novel beta-agarase from marine Alteromonas sp. SY37-12 and its degrading products. Appl. Microbiol. Biotechnol. 2006, 71, 833-839. [CrossRef] [PubMed]

33. Lu, X.; Chu, Y.; Wu, Q.; Gu, Y.; Han, F.; Yu, W. Cloning, expression and characterization of a new agarase-encoding gene from marine Pseudoalteromonas sp. Biotechnol. Lett. 2009, 31, 1565-1570. [CrossRef] [PubMed]

34. Long, M.; Yu, Z.; Xu, X. A novel beta-agarase with high $\mathrm{pH}$ stability from marine Agarivorans sp. LQ48. Mar. Biotechnol. 2010, 12, 62-69. [CrossRef] [PubMed]

35. Oh, C.; Nikapitiya, C.; Lee, Y.; Whang, I.; Kim, S.J.; Kang, D.H.; Lee, J. Cloning, purification and biochemical characterization of beta agarase from the marine bacterium Pseudoalteromonas sp. AG4. J. Ind. Microbiol. Biotechnol. 2010, 37, 483-494. [CrossRef]

36. Lee, D.G.; Jang, M.K.; Lee, O.H.; Kim, N.Y.; Ju, S.A.; Lee, S.H. Over-production of a glycoside hydrolase family 50 beta-agarase from Agarivorans sp. JA-1 in Bacillus subtilis and the whitening effect of its product. Biotechnol. Lett. 2008, 30, 911-918. [CrossRef] [PubMed]

37. Zhu, Y.; Zhao, R.; Xiao, A.; Li, L.; Jiang, Z.; Chen, F.; Ni, H. Characterization of an alkaline beta-agarase from Stenotrophomonas sp. NTa and the enzymatic hydrolysates. Int. J. Biol. Macromol. 2016, 86, 525-534. [CrossRef]

38. Yang, M.; Mao, X.; Liu, N.; Qiu, Y.; Xue, C. Purification and characterization of two agarases from Agarivorans albus OAY02. Process. Biochem. 2014, 49, 905-912. [CrossRef]

39. Ma, C.; Lu, X.; Shi, C.; Li, J.; Gu, Y.; Ma, Y.; Chu, Y.; Han, F.; Gong, Q.; Yu, W. Molecular cloning and characterization of a novel beta-agarase, AgaB, from marine Pseudoalteromonas sp. CY24. J. Biol. Chem. 2007, 282, 3747-3754. [CrossRef]

40. Osumi, Y.; Kawai, M.; Amano, H.; Noda, H. Purification and structure of oligosaccharides from porphyran degradated by enzymes from Arthrobacter sp. S-22. Nippon Suisan Gakkaishi 1998, 64, 88-97. [CrossRef]

41. Chen, H.M.; Zheng, L.; Lin, W.; Yan, X.J. Product monitoring and quantitation of oligosaccharides composition in agar hydrolysates by precolumn labeling HPLC. Talanta 2004, 64, 773-777. [CrossRef]

42. Li, J.; Han, F.; Lu, X.; Fu, X.; Ma, C.; Chu, Y.; Yu, W. A simple method of preparing diverse neoagaro-oligosaccharides with beta-agarase. Carbohydr. Res. 2007, 342, 1030-1033. [CrossRef]

43. Morrice, L.M.; McLean, M.W.; Long, W.F.; Williamson, F.B. $\beta$-Agarases I and II from Pseudomonas atlantica. Eur. J. Biochem. 1983, 116-117, 576-579. [CrossRef]

44. Kazlowski, B.; Pan, C.L.; Ko, Y.T. Separation and quantification of neoagaro-and agaro-oligosaccharide products generated from agarose digestion by beta-agarase and $\mathrm{HCl}$ in liquid chromatography systems. Carbohydr. Res. 2008, 343, 2443-2450. [CrossRef]

45. Kazlowski, B.; Pan, C.L.; Ko, Y.T. Monitoring and preparation of neoagaro- and agaro-oligosaccharide products by high performance anion exchange chromatography systems. Carbohydr. Polym. 2015, 122, 351-358. [CrossRef]

46. Han, J.P.; Huang, Y.Y.; Ye, J.; Xiao, M.T. Screening and identification of a bacterium capable of converting agar to neoagaro oligosaccharides. Acta Microbiol. Sin. 2015, 55, 1126-1132.

47. Fan, J.M.; Xie, C.Q.; Jia, J.; Yin, X.U.; Zhang, C.X. Opitimization of extraction processing on polysaccharides from Pleurotus eryngii by cellulase enzymolysis. Food. Sci. Tech. 2013, 38, 192-196. [CrossRef]

48. Liu, J.B.; Zhao, S.N.; Lin, S.Y.; Zhang, Y.; Ren, M. Process optimization on extracting collagen with enzymolysis method from black fungus. Trans. Chin. Soc. Agric. Eng. 2012, 28, 282-286. [CrossRef]

49. Hong, S.J.; Lee, J.H.; Kim, E.J.; Yang, H.J.; Park, J.S.; Hong, S.K. Toxicological evaluation of neoagarooligosaccharides prepared by enzymatic hydrolysis of agar. Regul. Toxicol. Pharm. 2017, 90, 9-21. [CrossRef]

50. Mei, J.; Shao, J.; Wang, Q.; Wang, H.; Yi, Y.; Ying, G. Separation and quantification of neoagaro-oligosaccharides. J. Food. Sci. Tech. Mys. 2013, 50, 1217-1221. [CrossRef]

(C) 2019 by the authors. Licensee MDPI, Basel, Switzerland. This article is an open access article distributed under the terms and conditions of the Creative Commons Attribution (CC BY) license (http://creativecommons.org/licenses/by/4.0/). 